\title{
Discussions on the Improvement of the
}

\section{Internal Control in SMEs}

\author{
Linjie Jiang \\ College of Industry and Commerce, Tianjin Polytechnic University \\ No. 399 Binshui road, Xinqing district, Tianjin 300387, China \\ E-mail: jianglinjie1023@126.com
}

Xuedong Li

College of Industry and Commerce, Tianjin Polytechnic University, China

E-mail: lixuedong1978@126.com

\begin{abstract}
With the development of the economic, the problems of internal control in SMEs became more and more prominent, Which mainly express at neglecting of the management, highlighting the internal control environment, information distortion, ineffective supervision ect, has become an important reason which constraint the further development of SMEs. Therefore, this article put forward corresponding solutions for the problems of the SMEs internal control, hope it cans plays a role on the development of SMEs.
\end{abstract}

Keywords: SMEs, Internal Control, Improvement

\section{The necessity of improving internal controls for SMEs}

The Small and Medium Enterprise (SMEs) are very important force for economic and social development. They played important part in increasing national income, providing tax revenue and jobs. However, with the development of SMEs, their internal problems are gradually exposed, especially in the financial crisis, a large number of small and medium enterprises closed down, the reason is: the construction of internal control deficiency of SMEs. Therefore, in current situation, how to build and improve the internal control of small and medium enterprises, how to play the effectiveness of internal control to make sure enterprises have normal, reasonable operation is particularly critical.

In May 2008, Ministry of Finance, Securities and Futures Commission, the Audit Commission, China Banking Regulatory Commission, China Insurance Regulatory Commission issued the new "Basic Standards of Internal Control of Enterprises". And it will be officially implemented in the context of listed companies on July 1, 2009. Meanwhile encouraging large and medium enterprises carry out it, providing the large enterprises and listed companies on how to build a set of internal control standards. But it is still not related to SMEs in the standards. That is to say, so far, there is no clear standard to guide SMEs on how to build internal controls.

\section{The Problems of Internal Control of SMEs}

\subsection{The management neglects the internal control and don't have risk awareness}

Due to the business scale, human resource, financial and its own conditions ect, many SMEs under the ownership and franchise's restrictions, unwilling to establish the standard internal control system. They believe that establishing internal control system is a high cost method, which will bring heavy burden to the enterprise and maybe without significant results can not compare with the managers manage all aspects of business directly. According to the survey, The SMEs don't recognize the internal management problem has become a common phenomenon. From the results of survey, only $6.8 \%$ of the enterprises think that it is necessary to improve their internal management (Yearbook of China SMEs 2003). Meanwhile, the enterprise management has poor awareness of risk and not accurate to the operate situation. The enterprise lacks of physical risk warning mechanism for every occurrence of business, financing and use of capital, shop management and so on.

\subsection{Prominent problems within the enterprise environment}

Internal environment is the general term of various internal factors: which affected and limited the internal control system established and implementation, is the basis for the implementation of internal control. The 
internal environment included: governance, setting of institutions, corporate culture, human resource policies ect. The internal environment of SMEs is imperfect, mainly in: many SMEs are family management, ownership and management are in one hand, and doesn't establish specification and effective governance; Organization doesn't cover all areas and aspect of business; Managers don't pay attention to corporate culture or have a wrong understanding corporate culture, only on its form, not to content, think the corporate culture the same as Corporate image; the SMEs don't have enough attractive for personnel, the staffs generally with few technology, the majority of personnel don't have ability for their jobs, while companies don't have a clear system in staffs' employing, training, rewards and penalties, assessment, this leads to the loss of many talented employees. According to Sina net survey, about $78 \%$ of employees are in an unsatisfied state in China's enterprises.

\subsection{Distortion of accounting information, poor management communication}

As the basic accounting work for SMEs is poor, financial management function can not fully play, this made the companies finance department, custody department, and the use of department can not be mutually restrict, account statement, account card, account discrepancies made accounting information distortion, which influences management decisions. Meanwhile, the sectors transfer of information each other are slow and poor quality, so all departments can not receive timely first-hand information on the information reflected accordingly.

\section{4 lack of effective supervision mechanisms}

At present, most SMEs not set the appropriate internal audit bodies, and the management take no count of the internal supervision mechanism. Even if an internal audit agency be set up, as lacks independence, a large of enterprise employees accept bribes, annexation property by supervise vulnerabilities within the enterprise, and the phenomenon of unauthorized diversion of fund is serious, so that internal supervision become a mere formality. Meanwhile, because of the supervision system incompletely, we can not full play its role of supervision and inspection, so that enterprise management can not evaluate the accounting information and the performance of different departments properly.

\section{The measures of improving internal controls for SMEs}

\subsection{Strengthening enterprise managements, emphasis on internal controls, and enhance the risk consciousness}

(1) As a business manager who need to emphasize and propagandize the nature and importance of the internal control, organize and lead all staff to set up a rounded, suitable internal control system to make middle managers and ordinary employees see the importance of the internal control to enterprise develop, deepen their understanding of the whole process of the internal control and job descriptions respectively. At the same time, managers should teach others by your example, compliance with the norms established to set a good example for all staff and establish a scientific evaluation system to supervise the implementation of the internal control.

(2) The management personnel should receive a training about legal knowledge so as to improve competence in solving problems by law, establish the early-warning mechanism of risk in company and focus on each transaction contract performance to ensure that transaction contract fulfill on schedule, establish long-term mechanism of accounts receivable management, bring advanced inventory system into force in the enterprise, and strengthen the control of the accounts receivable turnover and the inventory turnover to prevent the shortage of corporate funds.

\subsection{Improving the internal environment construction}

Internal environment refers to the basis of the internal control, only improve the internal environment can reduce the establishment of the inherent limitations of internal controls effectively, and improve the efficiency of internal control.

(1) According to the relevant laws and regulations, SMEs should establish a reasonable internal structure, give full play to the strength of the collective power to avoid excessive concentration of rights. Meanwhile, according to their characteristics, in accordance with the powers, responsibilities and benefits of principles, divide the relevant departments of different functions scientific to achieve simple and efficient purposes.

(2) In fact, any enterprise has its own corporate culture. Not to mention what is good, not to mention what is advanced, however, there is one thing we can see, the measure of a good or bad corporate culture, advanced or backward, effective or ineffective, the standard is what we call employee satisfaction (Jun Tang winner Lecture Theatre). Therefore, under the leadership of enterprise managers, from the concept of staff itself, establish common values of all members, emphasizing caring, respect, trust; according to its own operating characteristics and historical heritage, while absorbing advanced foreign culture, combined with their actual conditions, thereby enabling the formation of corporate culture has its own characteristics, so as to enhance the competitiveness of 
enterprises.

(3) SMEs human resource building include that description of each position, a clear division of labor jobs, the choice of targeted personnel into the post, and ensure that every post employees can have the corresponding ethical and professional competence. Meanwhile, according to the realities of enterprise, the members of the organization are trained regularly to increase their professional skills and proficiency in work.

\subsection{Improving the internal information system strengthening the internal communication}

Information and communication are important conditions for the implementation of internal control. SMEs should establish a two-way information exchange channels within the enterprise, form a top-down information dissemination channel and a bottom-up information reported channel. Through this channel we can ensure that all employees fully understand the information that relevant to their duties. At the same time, strengthen the training of accountants in business and ethics, and raise the overall quality of accounting department personnel, and strengthen supervision on the quality of accounting information system, to minimize the incidence of distortion of accounting information. Finally, we must seek to create a favorable environment in company to foster active communication awareness between management and staff.

\subsection{Improving corporate oversight mechanisms, enhance the management on Supervision}

Supervision and inspection of enterprises is a process which is an important guarantee to the implementation of internal control, inspect and assess the viability, rationality and effectiveness of the internal control, and form a written report ultimately. The internal supervision not only come true through daily, constantly monitors, but also achieved by individually, discontinuously monitors. First of all, make incompatible duties are separated by reform oversight bodies, divide supervision and the functions of institutions scientifically, set operating post reasonably, at the same time, a person or a department must communicate with other people or department, so that the internal supervision system would be really implemented. Second, under the guidance of the enterprise management, enhancing all staffs consciousness of supervision and subject yourself to supervision, so as to change the way of the management modality. Finally, clear the main responsibility of several departments, strengthen the sense of responsibility of the unit people in charge. Meanwhile, SMEs should increase supervision with the help of social supervision and other external forces to guarantee the healthy and rapid development of SMEs.

\section{References}

Gao Xiu-feng. (2008). Improving the Internal Control System of Small and Medium Enterprises. Shan Xi Finance and Tax, (6)

He Li-fen. (2006). The Construction Of SMES' Internal Control System. Economic Survey.

Management Informationization. (2009). (14)

Zhou Chao. (2009). Reach on the problems of SMEs' Internal Control. Money CHINA (Academic Edition) (8)

Zhu Rongen, Ying Wei \& Yuan Min. (2005). The Enterprise Internal Control System Design. Shanghai Finance and Economics Press. 